\title{
Quebras Estruturais Sistêmicas e Efeito Threshold na Dinâmica dos Preços do Boi Gordo: o caso das regióes Sudeste e Centro-Oeste
}

\author{
Thiago Costa Soares ${ }^{1}$ e Luckas Sabioni Lopes²
}

\begin{abstract}
Resumo: Este estudo objetivou analisar os possíveis efeitos de quebras estruturais sobre a integração de preços e os custos de transação nos mercados de boi gordo das regiões Sudeste e Centro-Oeste do País, utilizando dados mensais para os anos entre 1980 e 2012. A amostra foi dividida em diferentes períodos de acordo com um teste de quebras múltiplas que ocorrem em datas comuns a todas as séries de preços nesses estados. Em seguida, estimou-se o modelo de cointegração com threshold, M-TAR, para controlar os efeitos da assimetria no ajustamento dentro de cada subamostra. Pelos resultados obtidos, foram identificadas duas importantes quebras estruturais: a primeira, relacionada ao período hiperinflacionário, e a segunda, à crise internacional de 2007/2008. Essas quebras são determinantes para o entendimento da dinâmica conjunta das séries. Percebeu-se, por exemplo, que os custos de transação foram maiores no período hiperinflacionário, muito embora houvesse cointegração nesta conjuntura. Na última subamostra, de instabilidade externa, a hipótese de relação estável em longo prazo foi rejeitada, não obstante com baixos custos de transação. Ressalta-se, assim, a necessidade de se considerar a possibilidade de quebras estruturais em análises de integração de preços da commodity em questão.
\end{abstract}

Palavras-chaves: Boi gordo, integração de mercados, quebras estruturais, Sudeste, Centro-oeste.

Abstract: In this paper, we aimed to investigate beef cattle markets integration, when taking into account structural breaks in multivariate (auto)regressions, and transaction costs, in the Southeast and Central-West regions in Brazil. Data set is monthly, ranging from 1980 to 2012. Our methodological approach is built on two main blocks: first, time series are divided into smaller samples sharing common characteristics, according to the structural breaks test due to Qu and Perron (2007); second, momentum threshold model (M-TAR, ENDERS; SIKLOS, 2001) is employed addressing to issues as cointegration

1. Universidade Federal de Juiz de Fora. Governador Valadares, Minas Gerais, Brasil. E-mail: thiago.costa@ufjf.edu.br

2. Universidade Federal de Juiz de Fora. Governador Valadares, Minas Gerais, Brasil. E-mail: luckas.lopes@ufjf.edu.br 
and asymmetrical adjustment. Our results show two significant breaks, one related to the hyperinflationary period, and another to the 2007/2008 financial crisis. Moreover, those breaks are decisive to understand the time series dynamics. For instance, in the hyperinflationary sample, transaction costs were higher, although markets were integrated. Conversely, between 2007 and 2012, prices were not synchronized, while transaction costs were almost non-significant. Thus, integration analyses that do not consider structural breaks may mislead some relevant aspects of the data.

Key-words: Beef cattle, market integration, structural breaks, Southeast, Central-West, Brazil.

http://dx.doi.org/10.1590/1234-56781806-9479005302009

\section{Introdução}

A produção de commodities agropecuárias no Brasil responde por parcela significativa da geração de emprego e renda, além de estar relacionada com questões de segurança alimentar. Por esse motivo, um número crescente de estudos tem buscado melhor compreensão do funcionamento dos mercados agropecuários. Uma vertente em franca expansão nos últimos anos se refere à análise do grau de integração e, portanto, da forma em que os choques são transmitidos entre diferentes localidades (ZILLI et al., 2008).

Nesse sentido, devido à usual não estacionariedade das séries de preços das commodities brasileiras, a análise de cointegração ${ }^{3}$ tornou-se uma das principais técnicas utilizadas, uma vez que ela corrige o problema de raízes unitárias e permite avaliar as características dos mercados no curto e no longo prazo. Destacam-se, por exemplo, os trabalhos de Bressan e Lima (2002), Abitante (2008), Moraes et al. (2009) e Mattos et al. (2009).

Em razão da sua relevância relativa, a bovinocultura é objeto de estudo de grande parte das análises de integração feitas no Brasil. Como visto em Abitante (2008), o Brasil é um dos maiores produtores de gado do mundo e o principal

3. Metodologia originalmente proposta por Engle e Granger (1987) e, mais tarde, refinada por Johansen (1988). exportador de carne bovina. Dados revelam que o País detém cerca de $17 \%$ do rebanho mundial, com 170 milhões de cabeças de gado, concentrando a produção nas regiões Sudeste e Centro-Oeste do País. Estados como Mato Grosso, Mato Grosso do Sul, Minas Gerais, São Paulo e Goiás, por exemplo, representam $60 \%$ do abate de bovinos machos no território nacional (ZILLI et al., 2008).

Ao utilizar abordagens de integração de mercados, Bressan e Lima (2002) buscaram estimar os retornos das operações de compra e venda no mercado futuro de boi gordo, a fim de indicar potencialidades e limitações das negociações dessa commodity, através da metodologia de Box e Jenkins (1970). Abitante (2008), por sua vez, verificou a relação estatística entre o mercado spot (preço à vista) e o preço futuro do boi gordo, negociado na Bolsa de Mercadorias e Futuros (BM\&F) e na Chicago Board of Trade (CBOT). Já Morais et al. (2009) testaram a eficiência do mercado futuro de boi gordo brasileiro, assumindo a hipótese de prêmio de risco.

Não obstante, como mostram Mattos et al. (2009), os modelos econométricos tradicionais presumem que quaisquer choques nos preços, independente de sua magnitude, são transmitidos para o mercado quando a hipótese de integração é verificada. Tais formulações, portanto, desconsideram a possibilidade de custos de transação, podendo não refletir a verdadeira relação entre os mercados. Neste contexto, os parâme- 
tros estimados, além de enviesados, seriam inconsistentes.

Ressalta-se, ainda, que os estudos citados anteriormente não consideraram a possibilidade de ocorrência de mudanças estruturais no mercado do boi gordo brasileiro ao longo dos anos. Urso (2007), por exemplo, constatou que a produção bovina vem tentando reduzir custos de transação desde meados da década de 1990. Além disso, o ambiente macroeconômico brasileiro e o internacional constantemente passam por alterações relevantes, podendo-se destacar, entre outras, a estabilização advinda com o Plano Real. Dessa forma, ao não computar as quebras estruturais pelas quais os mercados do boi gordo possam ter passado, corre-se o risco de obter informações imprecisas a respeito da dinâmica temporal dos preços dessa commodity ${ }^{4}$.

Nesse sentido, o objetivo deste estudo é incorporar a influência das quebras estruturais sistêmicas sobre a integração e os custos de transação no mercado brasileiro de boi bordo. Procura-se, com isso, contribuir com a literatura especializada ao identificar os efeitos das mudanças ocorridas na economia nacional e internacional sobre a dinâmica dos preços, proporcionando bases mais adequadas para a formulação de políticas voltadas ao setor.

A análise se concentra nas regiões do Sudeste e Centro-Oeste, baseando-se em dados mensais que variam de janeiro de 1980 a junho de 2012. Utilizou-se o modelo Momentum-Threshold Autoregressive (M-TAR) para controlar os efeitos dos custos de transação e da assimetria no processo de ajustamento dos preços. A possibilidade de quebras estruturais múltiplas no mercado do boi gordo é considerada seguindo a abordagem de Qu e Perron (2007).

Além desta introdução, este artigo está organizado em mais quatro seções. A segunda seção apresenta a relevância da análise de integração dos mercados de commodities, do custo de

4. Ademais, modelos com threshold tendem a ser sensíveis às mudanças no período de estimação (ENDERS e SIKLOS, 2001), o que aumenta a necessidade de análises de quebras estruturais. transação e das quebras estruturais. A terceira leva em consideração a possibilidade de quebras estruturais nos preços do boi gordo, definindo subamostras com características semelhantes. A quarta apresenta os principais resultados e discussões. Por fim, a quinta seção traz as conclusões do estudo.

\section{Integração de mercado, custo de transação e quebras estruturais sistêmicas}

São discutidos, nesta seção, os modelos econômicos utilizados pela literatura para analisar a estrutura de integração de preços entre mercados. Entende-se por integração a transmissão de preços que ocorre entre localidades espacialmente separadas, denotadas por A e B, quando há um choque exógeno na praça $A$ e este choque é, então, repassado à praça $\mathrm{B}$ (ou vice-versa) (OBSTFELD e TAYLOR, 1997).

Alguns estudos têm atribuído especial atenção à arbitragem como razão para a transmissão de preços e, consequentemente, a integração de mercados (MATTOS et al., 2009; MEYER, 2004; BARRET, 2001) ${ }^{5}$. Especificamente para Mattos et al. (2009), a arbitragem ocorre quando um agente adquire uma commodity em uma localidade de menor preço e a revende em outras regiões, levando em consideração os custos envolvidos nessa atividade. Dessa forma, haverá integração entre duas praças sempre que os custos de transação forem suficientemente baixos. Caso contrário, não seria rentável para o agente realizar a arbitragem, e choques exógenos, neste cenário, não seriam transmitidos de uma localidade para as demais (BARRET, 2001).

A divergência entre os preços de localidades espacialmente separadas, quando os produtos são homogêneos, é resultado dos custos envolvidos na locomoção da produção. Tais custos incluem gastos com transporte, com a coleta de informa-

5. Meyer e von Cramon-Taubadel (2004) fazem uma ampla revisão de literatura a respeito da arbitragem no contexto de integração de mercados. 
ções e com seguros, por exemplo. Grande parte dos estudos de integração de mercados denota esses elementos, genericamente, pelo termo "custos de transação" (BARRET, 2002; ALAM et al., 2002; MEYER, 2004).

Portanto, a transmissão de preços entre diferentes praças pode estar relacionada aos custos de transação. Caso este último supere os ganhos com a arbitragem, os choques nos preços não serão repassados e, por isso, não haverá integração. Nota-se, então, a importância de considerar os custos de transação em análises dessa natureza.

Mattos et al. (2009) ressaltam que maiores custos de transação podem tornar o mercado segmentado, possuindo suas próprias demandas e ofertas, gerando, assim, perda de eficiência econômica. Por exemplo, um choque de preços positivo em certa localidade estimula, via arbitragem, direcionamento da oferta para a referida região, mitigando o efeito altista no preço nesta e, assim, aumentando o preço nas outras regiões (isto é, gerando convergência de preços). Assim, quanto menores os custos de transação, maior o grau de integração entre as diferentes localidades.

Neste artigo, os custos de transação são abordados com a metodologia de cointegração com threshold de Enders e Siklos (2001). Basicamente, a hipótese subjacente é de simetria no processo de ajustamento entre os mercados. Procura-se estimar um valor limiar para o qual a hipótese de simetria é testada, bem como a hipótese de baixos custos de transação. Contudo, uma inovação é introduzida na presente pesquisa, qual seja, a análise de como diferentes contextos econômicos podem afetar o próprio valor do limar. Realiza-se, assim, uma análise de quebras estruturais sistêmicas (QU e PERRON, 2007) no mercado de boi gordo antes de proceder com o estudo de cointegração.

Teoricamente, os custos de transação podem ser afetados pelas diversas conjunturas econômicas. Uma crise internacional, por exemplo, pode elevar muito a dificuldade de coleta de informações confiáveis, dado o elevado grau de incerteza existente nessa fase do ciclo econômico. Desse modo, a ocorrência de quebras estruturais no sistema de preços altera a forma na qual os mercados se relacionam, devendo ser considerada em análises como a feita na presente pesquisa.

\section{Metodologia}

\subsection{O Modelo Momentum-Threshold Autoregressive (M-TAR)}

A literatura tem mostrado que séries de preços de commodities são particularmente não estacionárias (ZILLI et al., 2008; BRESSAN e LIMA, 2002; MEYER, 2004). Portanto, em nível, não se deveria analisar a integração de mercados do boi gordo, pois choques de curto prazo não tendem a se dissipar no sistema de equações, tornando-o instável e inconsistente.

Não obstante, Johansen (1988) demonstrou que mesmo variáveis não estacionárias podem ter comportamentos temporais interligados se forem cointegradas de mesma ordem, ou seja, se forem estacionárias através do mesmo processo de diferenciação. Assim, apesar de haver desequilíbrios no curto prazo, eles podem ser corrigidos a cada período para garantir a estabilidade em longo prazo do modelo.

Nos últimos anos, a técnica mais utilizada em análises de integração tem sido a de modelos vetoriais de correção do erro - Vector Error Correction Model (VEC), pois ela permite, em um sistema definido de equações, analisar as relações de curto prazo, corrigindo os desequilíbrios ocasionados pela não estacionariedade das séries de preços, através da inclusão de um mecanismo que corrige os desvios em torno da relação de longo prazo entre os diferentes mercados.

Por outro lado, o modelo VEC pressupõe linearidade e simetria entre o ajustamento de preços e a magnitude dos choques exógenos. Em outras palavras, quaisquer choques conduzem à integração entre os mercados, desconsiderando os custos de transação envolvidos nesse processo (MATTOS et al., 2009).

Conforme mostra Meyer (2004), apenas haverá integração se os custos de transação forem 
suficientemente baixos. Este fato não é explicitamente controlado pelo modelo VEC, tornando-o mal especificado e com parâmetros enviesados, caso esses custos sejam significativos. Alam et al. (2012) reportam que infraestrutura inadequada, assimetria informacional, poder de mercado e custos de menu, entre outros, são fatores que podem contribuir para o aumento dos custos de transação.

Verifica-se que, caso os custos de transação não sejam considerados, a hipótese de cointegração de mercados pelo modelo VEC pode ser falsamente rejeitada. Por exemplo, mesmo que em uma situação de normalidade possa existir uma relação de cointegração entre os preços, com altos custos de transação, a arbitragem pode ser inviabilizada (ENDERS e SIKLOS, 2001).

Esta limitação incentivou a procura por métodos capazes de incorporar os efeitos dos custos de transação e assimetrias no processo de ajustamento em análises de integração. Entre os modelos estudados, destaca-se o Modelo Momentum-Threshold Autoregressive (M-TAR), introduzido por Enders e Siklos (2001), que considera, além da cointegração, a possível assimetria no processo de ajustamento dos preços aos choques e aos custos de transação.

O modelo M-TAR estabelece um limiar para captar assimetrias no processo de ajustamento de preços, quando houver, além de custos de transação, cointegração. A velocidade do ajustamento pode, então, ser diferente se os desvios estiverem abaixo ou acima de um determinado threshold, denotado por $\gamma$, conforme ilustrado pela Figura 1.

Verifica-se que o modelo proposto na Figura 1 apresenta duas possíveis trajetórias, uma para cada regime (Regime 1 e Regime 2). A relação entre o termo de correção de erro (TCE) defasado e o preço em primeira diferença descreve o ajustamento derivado da relação de longo prazo que corrige os desequilíbrios nas relações de curto prazo (ENGLE e GRANGER, 1987). Note-se que o Regime 1 , situado à esquerda do limiar $\gamma$, trata de uma região onde os desvios do equilíbrio de longo prazo são diferentes dos reportados no Regime 2 , sugerindo assimetria no ajustamento de preços. Por isso, a metodologia de ajustamento com threshold torna-se mais adequada, pois o limiar é uma medida dos custos de transação envolvidos.

O teste bivariado de cointegração de Engle e Granger (1987), bastante difundido na literatura, permite especificar os modelos:

$$
\begin{aligned}
& P_{A t}=\hat{\beta}_{11}+\hat{\beta}_{12} P_{B t}+\hat{\mu}_{1 t} \\
& P_{B t}=\hat{\beta}_{21}+\hat{\beta}_{22} P_{A t}+\hat{\mu}_{2 t}
\end{aligned}
$$

em que $\mathrm{P}_{\mathrm{At}}$ e $\mathrm{P}_{\mathrm{Bt}}$ são os preços dos mercados $\mathrm{A}$ e $\mathrm{B}$, respectivamente; os termos $\hat{\beta}$ são os parâmetros

Figura 1. A relação entre o termo de correção de erro (TCE) e o ajustamento do preço

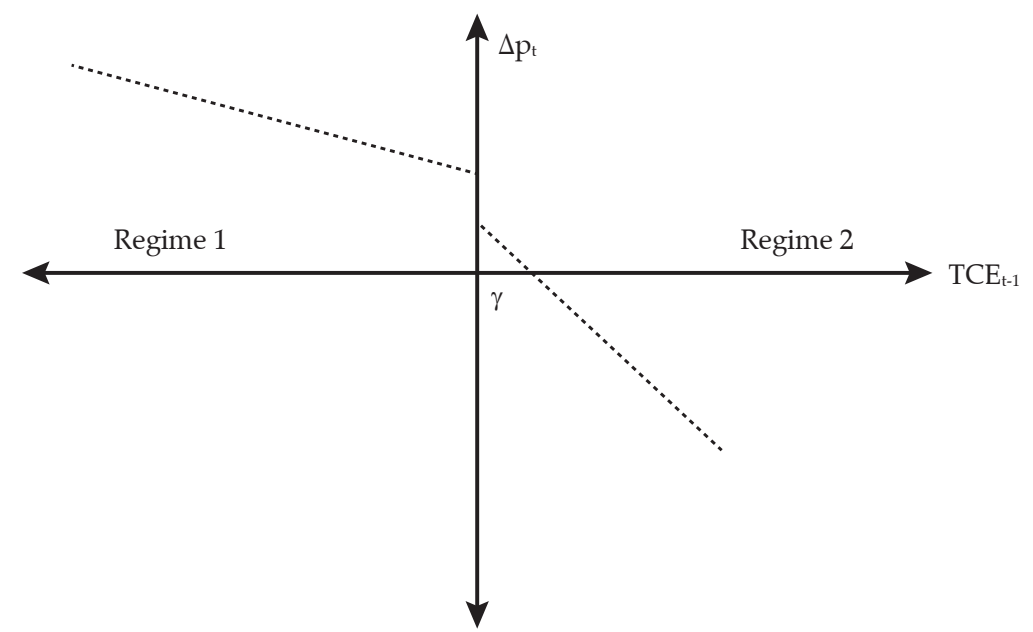

Fonte: Adaptado de Meyer (2004). 
de intercepto e coeficiente angular a serem estimados; e $\hat{\mu}$ representa os erros aleatórios em cada equação. Para haver cointegração, a combinação linear dos preços deve ser estacionária em nível, ou seja, $\hat{\mu}_{1 \mathrm{t}}=\mathrm{P}_{\mathrm{At}}-\hat{\beta}_{11}-\hat{\beta}_{12} \mathrm{P}_{\mathrm{Bt}} \sim \mathrm{I}(0)$.

Como pode ser visto, os custos de transação não são especificados no modelo (1), portanto, o comportamento dessa variável passa a ser incluído no erro estocástico. A abordagem de Enders e Siklos (2001) permite especificar a equação do teste de raiz unitária de Dickey e Fuller (1979), incorporando a assimetria no processo de ajustamento pela estimação de um valor threshold, conforme a equação (2):

$$
\Delta \hat{\mu}_{\mathrm{t}}=\mathrm{M}_{\mathrm{t}} \hat{\rho}_{1} \hat{\mu}_{\mathrm{t}-1}+\left(1-\mathrm{M}_{\mathrm{t}}\right) \hat{\rho}_{2} \hat{\mu}_{\mathrm{t}-1}+\sum_{\mathrm{i}=1}^{\rho-1} \phi_{1} \Delta \hat{\mu}_{\mathrm{t}-1}+\hat{\varepsilon}_{\mathrm{t}}
$$

em que $\hat{\varepsilon}_{t}$ é o termo de erro aleatório independente com média zero e variância constante, $\Delta \hat{\mu}_{t-1}$ são as séries de resíduos defasados (em diferenças) que objetivam controlar a possível autocorrelação serial dos resíduos e $\mathrm{M}_{\mathrm{t}}$ é definido por

$$
M_{\mathrm{t}}\left\{\begin{array}{l}
1, \text { se } \mu_{\mathrm{t}-1} \geq \gamma \\
0, \text { se } \mu_{\mathrm{t}-1}<\gamma
\end{array}\right.
$$

Segundo Enders e Siklos (2001), a condição necessária e suficiente para que $\mu_{\mathrm{t}}$ seja estacionário é $\rho_{1}<0, \rho_{2}<0$ e $\left(1+\rho_{1}\right)\left(1+\rho_{2}\right)<1$ para qualquer valor de $\gamma$. Neste contexto, o ajustamento é simétrico se, e somente se, $\rho_{1}=\rho_{2}$. Então, o modelo de Enders e Siklos (2001) se torna equivalente ao de Engle e Granger (1987). Se houver um único vetor de correção de erro no modelo (1), os parâmetros $\rho_{1}$ e $\rho_{2}$ fornecerão as velocidades de ajustamento dos preços acima e abaixo do threshold, respectivamente. O modelo apresentado em (2) e (3) é chamado de M-TAR, pois as séries apresentam mais "momentum" em uma direção que em outra.

Não obstante, o parâmetro threshold, a priori, é desconhecido. Portanto, é necessário estimá-lo conjuntamente com os parâmetros de ajustamento. Chan (1993) mostrou, através de um estudo de Monte Carlo, que a minimização da soma dos quadrados residuais do modelo ajustado conduz a um valor threshold consistente. A metodologia proposta consiste em estimar a relação (1), obter os resíduos e ordená-los, do menor para o maior, descartando os $30 \%$ valores extremos. Os demais 70\% dos resíduos são considerados possíveis thresholds. Para cada possível limiar, são estimadas as equações (2) e (3). O modelo que obtiver a menor soma dos quadrados dos residuais fornecerá a estimativa mais apropriada do threshold.

Conforme apontam Cunha et al. (2010), a estimativa $\gamma$ é uma aproximação dos custos de transação, pois valores abaixo de um determinado limite podem não ser repassados no sistema de preços e, portanto, não conduzirão ao ajustamento que garante a integração dos mercados.

Portanto, o modelo proposto por Enders e Siklos (2001) é condizente com a inclusão dos custos de transação no mercado de boi gordo, pois considera os ganhos com arbitragem, a integração de mercados e as assimetrias entre as velocidades de ajustamento. Os autores derivaram os valores críticos das estatísticas $\Phi(\mathrm{M})$ e t - Max(M) para testar as hipóteses $\rho_{1}=\rho_{2}=0$ e as hipóteses individuais dos parâmetros $\rho_{1}$ e $\rho_{2}$, respectivamente. A hipótese $\rho_{1}=\rho_{2}$ é testada pela aplicação de um teste $\mathrm{F}$.

A abordagem de Enders e Siklos (2001), contudo, é sensível à possiblidade de quebras estruturais, isto é, valores dos parâmetros de ajustamento e de limiar, por exemplo, podem variar de acordo com a conjuntura econômica. Por isso, a próxima subseção deste artigo aborda a necessidade da consideração deste fenômeno em análises de cointegração e custos de transação. Metodologicamente, segue-se a proposta de Qu e Perron (2007), descrita a seguir.

\subsection{Quebras estruturais múltiplas no sistema de preços}

Nesta seção é descrito o método utilizado para determinar as quebras estruturais múltiplas que ocorrem em pontos comuns a todas as séries do sistema de equações autorregressivas. Tal abordagem é interessante tanto por razões 
estatísticas como econômicas. Estatisticamente, a consideração de quebras estruturais em sistemas multivariados proporciona a estimação de datas para as mudanças com intervalos de confiança menores, isto é, com maior grau de confiabilidade (BAI et al., 1998; QU e PERRON, 2007). Por sua vez, em termos econômicos, a existência de quebras comuns ao conjunto de variáveis indica datas de mudanças relevantes que afetam o mercado como um todo, proporcionando a análise de alterações estruturais sistêmicas e a avaliação de suas prováveis causas.

Procura-se, ao estimar datas de quebras estruturais, definir e caracterizar subamostras específicas em que a hipótese de integração dos mercados é avaliada. Associa-se, assim, a evolução conjunta dos preços de mercado dentro de diferentes contextos econômicos. As séries temporais analisadas correspondem aos estados do Centro-Oeste e Sudeste do Brasil, variando de janeiro de 1980 a junho de 2012, contando, assim, com 390 observações. Os dados foram obtidos na Fundação Getúlio Vargas (FGV-DADOS). Todas as variáveis foram deflacionadas a preços de maio de 2011 e dessazonalizadas com o método Census X-12. As observações intermediárias faltosas, oito na série de Minas Gerais e 12 na de Mato Grosso do Sul, foram linearmente interpoladas. Os estados incorporados neste estudo representam mais de $60 \%$ do abate nacional de bovinos (IBGE, 2014).

No presente artigo, no momento da estimação das datas de quebras, utiliza-se a abordagem proposta por Qu e Perron (2007). Tal método permite alterações nos interceptos, nos coeficientes angulares e na matriz de variância e covariância dos erros, sendo aplicável aos casos de modelos VAR, alguns tipos de painéis lineares e em regressões aparentemente não relacionadas (SUR).

Assumiu-se que as sete séries de tempo se comportam como um VAR (1) em nível, por duas razões. Primeiro, esse modelo minimiza o critério de informação Bayesiano (BIC) no sistema VAR sem quebras estruturais. Segundo, esse é um modelo parcimonioso em vista do elevado número de parâmetros a serem estimados ${ }^{6}$. Assim, o sistema autorregressivo pode ser representado, em forma compacta, da seguinte maneira:

$$
\mathrm{p}_{\mathrm{t}}=\left(\mathrm{I}_{7} \otimes \mathrm{z}_{\mathrm{t}}^{\prime}\right) S \beta_{\mathrm{j}}+\mathrm{u}_{\mathrm{t}}
$$

em que, $p_{\mathrm{t}}$ é o vetor $(7 \times 1)$ de preços do boi gordo nos estados de GO, MS, MT, ES, MG, SP e RJ; $t$ é o indexador de tempo; $I_{7}$ representa uma matriz identidade de ordem sete; $\mathrm{z}_{\mathrm{t}}^{\prime}=\left(1, p_{\mathrm{GO}, \mathrm{t}-1}, p_{\mathrm{MS}, \mathrm{t}-1 \mathrm{t}}\right.$ $\left.p_{\mathrm{MT}, \mathrm{t}-1}, p_{\mathrm{ES}, \mathrm{t}-1}, p_{\mathrm{MG}, \mathrm{t}-1,1}, p_{\mathrm{SP}, \mathrm{t}-1}, p_{\mathrm{R}, \mathrm{t}-\mathrm{1}-\mathrm{l}}\right)$; e a matriz $S$ seleciona os regressores aparecendo em cada equação. Especificamente neste artigo, $S=I_{56}$, e o número 56 se origina do fato de o modelo ter um intercepto e sete coeficientes autorregressivos em cada regressão do sistema VAR. Percebe-se que $\beta_{\mathrm{j}}$ é um vetor coluna que inclui todos os coeficientes no regime $j$, ou seja, $\beta_{j}=\left(\beta_{1, j}, \ldots, \beta_{56, j}\right)^{\prime}$. Assim, definindo $m$ como o número de quebras, e $\beta$, vetor coluna obtido pelo empilhamento dos coeficientes nos diferentes regimes, tem-se que $\beta$ $=\left(\beta^{\prime}{ }_{1}, \ldots, \beta_{m+1}^{\prime}\right)^{\prime}$. Por fim, $u$ representa o vetor de erros aleatórios com matriz de variâncias e covariâncias $\sum$.

Seja agora $T_{\mathrm{i}}, i=1, \ldots, m, \mathrm{a}(\mathrm{s})$ data(s) estimada(s) de quebra(s) no VAR (1), e $T$ uma dada partição da amostra, tal que $T=\left(T_{1}, \ldots\right.$, $\left.T_{\mathrm{m}}\right)$. O processo de estimação tem como objetivo encontrar valores para $\left(T_{1}, \ldots, T_{\mathrm{m}}, \beta, \Sigma\right)$ que maximizam o logaritmo da função de quase-verossimilhança representada abaixo, condicional a $T$ (equação 5):

$$
\mathrm{L}_{\mathrm{T}}(\mathrm{T}, \beta, \Sigma)=\prod_{\mathrm{j}=1}^{\mathrm{m}+1} \prod_{\mathrm{t}=\mathrm{T}_{\mathrm{j}-1+1}+1}^{\mathrm{T}_{\mathrm{j}}} \mathrm{f}\left(\mathrm{p}_{\mathrm{t}} \mid \mathrm{z}_{\mathrm{t}}, \beta_{\mathrm{j}}, \Sigma_{\mathrm{j}}\right)
$$

Em que, na equação (5), a função densidade de probabilidade é assumida como gaussiana, isto é,

$$
\begin{aligned}
& f\left(p_{t} \mid z_{t} ; \beta_{j}, \Sigma_{j}\right)=\frac{1}{(2 \pi)^{n / 2}\left|\Sigma_{j}\right|^{1 / 2}} \\
& \exp \left\{-\frac{1}{2}\left[p_{t}-z_{t}^{\prime} \beta_{j}\right]^{\prime} \sum_{j}^{-1}\left[p_{t}-z_{t}^{\prime} \beta_{j}\right]\right\}
\end{aligned}
$$

6. Adicionalmente, conforme Bueno (2008) aponta, o teorema de Wold demonstra que qualquer série temporal pode ser representada por um $\mathrm{MA}(\infty)$. Portanto, por invertibilidade, modelos AR(1) são suficientes para expressar o comportamento da série no tempo. 
A intuição básica do processo de estimação se dá como a seguir. Primeiramente, define-se um número máximo de quebras, por exemplo, $k$. A partir disso, o algoritmo particiona a amostra em diversos pontos no tempo, assumindo as diferentes possibilidades de quebras $(1, \ldots, k)$, guardando os valores encontrados para a função de quase-verossimilhança em uma matriz triangular. Suponha-se, agora, que o valor ótimo encontrado para $m$, isto é, aquele que gera a maior soma registrada na referida matriz, seja um valor $r, 0 \leq r \leq k$. A partir disso, o procedimento finaliza fornecendo as estimativas dos parâmetros nas $r+1$ diferentes amostras. Esses cálculos foram feitos no software GAUSS 10.

Neste artigo, concentra-se em $k=3$, permitindo, portanto, a estimação de até 224 coeficientes de intercepto e inclinação (sete equações, com oito parâmetros, em até quatro amostras), além da estimação das matrizes de variância e covariância dos erros aleatórios. Sistemas maiores poderiam alcançar níveis de complexidade crescentes, aumentando o tempo de execução do algoritmo e a possibilidade de problemas com a estimação. Adicionalmente, como é comum em análises de quebras estruturais, escolheu-se o valor de 15\% para o parâmetro de trimming.

\section{Resultados e discussão}

\subsection{Análise das quebras estruturais sistêmicas}

A Tabela 1 mostra as datas de quebras estimadas pelo método. Os testes apresentados nesta tabela foram construídos de maneira sequencial, considerando, primeiramente, a possibilidade de apenas uma quebra e, em seguida, duas e três quebras.

Desse modo, a primeira data a ser destacada pelos dados é a mais dominante no sistema. A apresentação das informações segue o formato "ano: mês". Assim, quando se considera apenas uma quebra estrutural, ela é estimada em fevereiro de 2007 (2007:02, em negrito na Tabela 1). Observa-se que o intervalo de confiança da mudança é bastante estreito, variando de dezembro de 2006 a março de 2007. Na última coluna, denominada SupLR, encontra-se a estatística de teste para a hipótese nula de nenhuma quebra contra a alternativa de uma quebra estrutural no sistema VAR. O valor calculado de 1002 é extremamente significativo, rejeitando fortemente a hipótese de completa estabilidade nos parâmetros do modelo econométrico.

A segunda quebra mais relevante destacada pelo método ocorre em, aproximadamente, 1995. No modelo com duas quebras, especificamente, essa mudança está datada em julho do ano citado. Em seguida, a terceira quebra é estimada em março de 2002 (2002:03). Observa-se, porém, que os intervalos de confiança de $90 \%$ para a especificação com três quebras ficam mais largos, denotando maior incerteza das estimativas nessa especificação.

Na Tabela 2, é feita uma completa caracterização das mudanças ocorridas no sistema, considerando, incialmente, as três datas de quebras: 1994:12, 2002:03 e 2007:01.

Tabela 1. Datas estimadas das quebras estruturais

\begin{tabular}{ccccc}
\hline Num. de quebras & & Datas estimadas & SupLR \\
\hline 1 (uma) & --- & -- & $2007: 02$ & $1002^{*}$ \\
\hline 2 (duas) & --- & $1995: 07$ & $2006: 12-2007: 03)$ & $2741^{*}$ \\
\hline 3 (três) & $1994: 12$ & $(1995: 07-1995: 08)$ & $(2007: 01-2009: 11)$ & $3248^{*}$ \\
\hline
\end{tabular}

Notas: 1) Intervalo de confiança de $90 \%$ entre os parênteses; Estatísticas SupLR significativas a 1\%.

Fonte: Resultados da pesquisa. 
Tabela 2. Informações cíclicas das séries nas subamostras consideradas

\begin{tabular}{|c|c|c|c|c|}
\hline Indicador & 1980-1994:11 & 1994:12-2002:02 & 2002:03-2006 & 2007-2012:06 \\
\hline \multicolumn{5}{|l|}{ Preço em Goiás } \\
\hline Média & 144,4 & 80,9 & 77,5 & 83,1 \\
\hline Desvio padrão & 42,6 & 7,8 & 9,2 & 7,8 \\
\hline Variação anual & $-4,8$ & 2,4 & $-8,4$ & 4,8 \\
\hline Persistência & 0,92 & 0,83 & 0,96 & 0,93 \\
\hline \multicolumn{5}{|l|}{ Preço em Mato Grosso do Sul } \\
\hline Média & 153,3 & 83,8 & 79,2 & 85,8 \\
\hline Desvio padrão & 43,9 & 7,2 & 9,1 & 8,5 \\
\hline Variação anual & $-4,8$ & 1,2 & $-7,2$ & 3,6 \\
\hline Persistência & 0,9 & 0,85 & 0,97 & 0,88 \\
\hline \multicolumn{5}{|l|}{ Preço em Mato Grosso } \\
\hline Média & 140,8 & 77,9 & 73,9 & 80,3 \\
\hline Desvio padrão & 43,7 & 7,6 & 7,6 & 8,8 \\
\hline Variação anual & $-4,8$ & 2,4 & $-7,2$ & 6 \\
\hline Persistência & 0,94 & 0,87 & 0,99 & 0,94 \\
\hline \multicolumn{5}{|l|}{ Preço em Espírito Santo } \\
\hline Média & 154 & 81,3 & 73,9 & 74 \\
\hline Desvio padrão & 48,1 & 8,1 & 7 & 7 \\
\hline Variação anual & $-4,8$ & 1,2 & -6 & 8,4 \\
\hline Persistência & 0,92 & 0,86 & 0,97 & 0,99 \\
\hline \multicolumn{5}{|l|}{ Preço em Minas Gerais } \\
\hline Média & 153,8 & 83,3 & 77,1 & 82,1 \\
\hline Desvio padrão & 45,3 & 9,2 & 8,2 & 8,4 \\
\hline Variação anual & $-4,8$ & 2,4 & $-7,2$ & 4,8 \\
\hline Persistência & 0,91 & 0,87 & 0,98 & 0,89 \\
\hline \multicolumn{5}{|l|}{ Preço em Rio de Janeiro } \\
\hline Média & 166 & 85 & 76,8 & 80,4 \\
\hline Desvio padrão & 48,4 & 8,9 & 7,5 & 8,8 \\
\hline Variação anual & $-4,8$ & $0,5^{\mathrm{NS}}$ & $-7,2$ & 6 \\
\hline Persistência & 0,92 & 0,86 & 0,99 & 0,98 \\
\hline \multicolumn{5}{|l|}{ Preço em São Paulo } \\
\hline Média & 167,5 & 89,2 & 82,1 & 85,5 \\
\hline Desvio padrão & 47,3 & 8,5 & 9,1 & 7,7 \\
\hline Variação anual & $-4,8$ & 1,2 & $-7,2$ & 2,4 \\
\hline Persistência & 0,91 & 0,82 & 0,97 & 0,93 \\
\hline Crescimento do abate (\% a.a.) & 2,7 & 0,5 & 5,2 & 1,6 \\
\hline Observações & 179 & 87 & 58 & 66 \\
\hline
\end{tabular}

Fonte: Resultados da pesquisa.

Os resultados apresentados na Tabela 2 são numerosos, porém, o padrão comportamental das séries é praticamente o mesmo em todos os casos. Primeiramente, verifica-se uma queda acentuada no preço médio, de aproximadamente $50 \%$, quando se compara a primeira amostra com as demais. Somente na última amostra, entre 2007 e 2012, houve pequena reversão desse movimento baixista nos preços, quando eles se elevaram em
7\% aproximadamente (quando comparado com o período anterior). De qualquer forma, o valor das médias das variáveis não parece ser o fator determinante das quebras ocorridas em 2002:03 e 2007:01.

Com respeito à variabilidade dos preços, verifica-se uma queda ainda mais notável na Tabela 2. Observa-se nas linhas "desvio padrão", a proxy padrão para a medição da volatilidade na litera- 
tura dos ciclos de negócios, que os preços eram cerca de cinco vezes mais instáveis na primeira amostra do que nas demais. Verifica-se, adicionalmente, que nas demais amostras o desvio padrão dos preços se estabiliza.

Conforme visto na Tabela 1, essa quebra coincide com o período de estabilização do nível geral de preços da economia, ocasionado, em grande parte, pelo Plano Real. A quebra de 1995, portanto, indica que este ano também foi marcado por uma mudança substancial na volatilidade dos preços do boi gordo.

A persistência das séries, medida por meio do coeficiente autorregressivo de primeira ordem, é elevada, conforme se vê na Tabela 2 . Na maioria das vezes, esse coeficiente é calculado acima de 0,85 , indicando funções de autocorrelação com decaimento lento, ou, em outras palavras, séries que transmitem por longos períodos de tempo o efeito de choques exógenos. Contudo, como acontece com a média dos preços, a persistência não foi fator determinante das duas quebras ocorridas após 1995.

A taxa de crescimento dos preços, relacionada com quebras estruturais na constante das autorregressões vetoriais, varia sistematicamente entre as diferentes amostras. É possível perceber, analisando a Tabela 2, que os preços caíram, em média, $4,8 \%$ ao ano entre 1980 e 1994:11; subiram cerca de $2 \%$ ao ano entre 1994:12 e 2002:02; e apresentaram taxa de variação anual de $-7 \%$ e $5 \%$, respectivamente, nas duas subamostras seguintes.

Essas quebras estruturais na taxa de crescimento anual foram decisivas para a determinação das datas de quebras apresentadas pelo método e descritas na Tabela 1. A este respeito, ilustra-se, na Figura 2, a dinâmica temporal das variáveis ao longo das amostras. Na parte $a$ dessa figura, é possível notar tendência de queda nos preços do boi gordo cotado nos sete estados, seguido de um período de alta na segunda amostra (parte $b$, Figura 2). Na terceira e quarta amostras, o padrão se repete, isto é, há uma tendência de queda entre 2002:03 e 2006:12 e uma de alta a partir de 2007.

Nesse sentido, o que o teste de quebras detectou, com certo peso, foram oscilações natu- rais do mercado bovino em razão do ciclo plurianual da produção. O ciclo plurianual ocorre com a seguinte lógica (MARGARIDO et al., 1996; REZENDE, 1992): i) em momentos de expectativas de quedas nos preços, em função de pioras esperadas no mercado bovino, os pecuaristas reagem abatendo as matrizes, o que, por sua vez, gera um aumento de oferta que acentua ainda mais a queda esperada dos preços. Veja-se, nesse sentido, que nas amostras em que a tendência dos preços é negativa, há um aumento significativo dos abates anuais (a penúltima linha da Tabela 2 contém essas informações); ii) chega-se a um ponto em que o número de matrizes é reduzido, gerando uma escassez de oferta e pressões altistas sobre os preços. Nesse momento, novas matrizes são retidas, porém, obedecendo ao período de amadurecimento dos animais. A alta dos preços segue até o momento em que houver novo excesso de animais para o abate. Percebe-se, assim, diminuição no número de abates em momentos de alta nos preços (Tabela 2).

Procedimentos estatísticos não conseguem discernir mudanças estruturais efetivas acontecidas no sistema de movimentações naturais dos mercados agrícolas, corporificadas como diferentes parâmetros em cada subamostra. As alterações das taxas de crescimento, por exemplo, ocorrem em datas muito similares a cada uma das séries individuais. Essa coincidência de eventos conduz o teste a gerar estimativas de datas de quebras altamente significativas que correspondem às diferentes taxas de crescimento dos preços. No sentido de tentar filtrar as alterações estruturais economicamente relevantes, são informados, na Tabela 3, os valores estimados para a volatilidade dos choques exógenos que afetaram os preços bovinos nas diferentes amostras.

Verifica-se que o período prévio ao Plano Real é bastante instável, assim como aquele após 2007. A alta variabilidade dos preços na primeira amostra é largamente documentada e se refere ao período hiperinflacionário da economia brasileira. A agricultura, nesta época, de modo geral, competia com alternativas de investimentos em ativos financeiros indexados (títulos públicos) e 
Figura 2. Séries de tempo em cada uma das quatro diferentes amostras

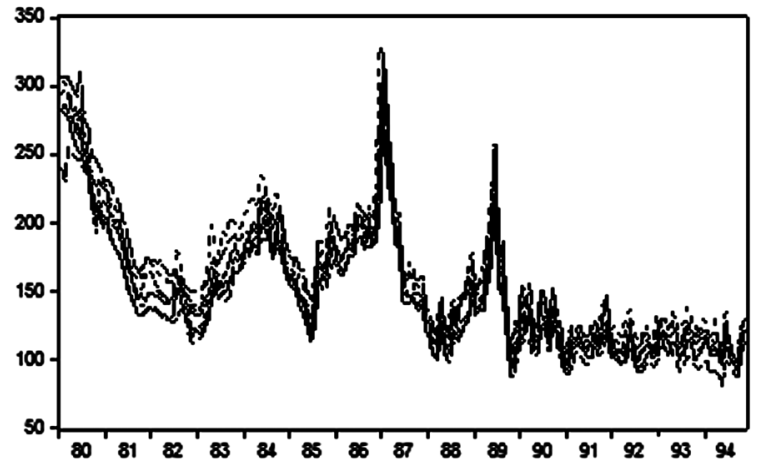

(a) Primeira amostra

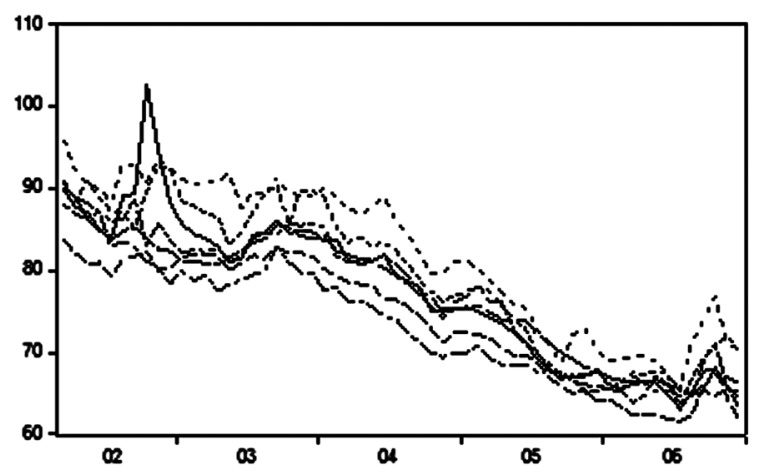

(c) Terceira amosta
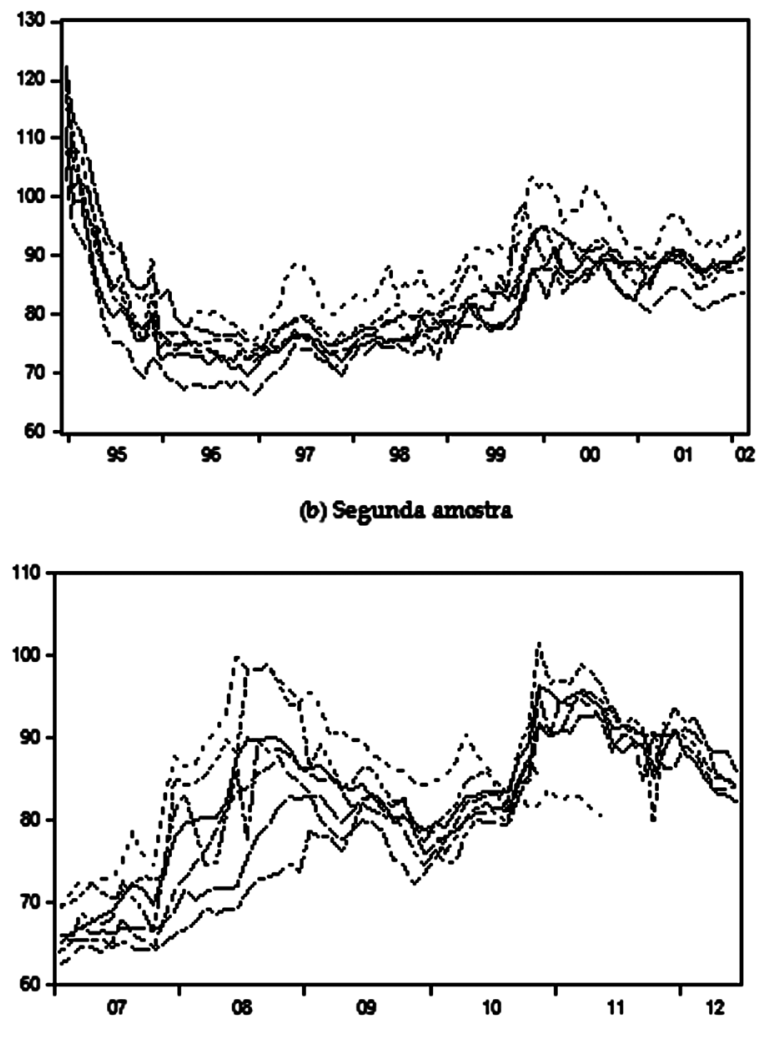

(d) Quarta amostra

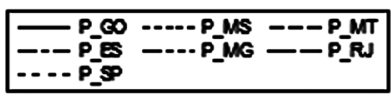

Fonte: Resultados da pesquisa.

Tabela 3. Desvio padrão dos choques exógenos sobre o sistema VAR

\begin{tabular}{lccccccc}
\hline \multicolumn{1}{c}{ Amostra } & P_GO & P_MS & P_MT & P_ES & P_MG & P_RJ & P_SP \\
\hline 1980 - 1994:11 & 24,2 & 26,1 & 25,9 & 27,5 & 27,8 & 26,6 & 30,7 \\
1994:12 - 2002:02 & 3,6 & 3,6 & 3,5 & 2,9 & 3,6 & 3,1 & 4,6 \\
2002:03 - 2006:12 & 2,5 & 2,6 & 1,8 & 1,9 & 2,2 & 1,5 & 2,1 \\
2007:01-2012:06 & 42,6 & 47,8 & 46,4 & 42,0 & 44,2 & 36,0 & 46,4 \\
\hline
\end{tabular}

Fonte: Resultados da pesquisa. 
enfrentava constantes mudanças na condução da política monetária e creditícia. Parâmetros importantes como a taxa de câmbio, o tabelamento de preços, o controle das importações e exportações e a taxa de juros eram alvo constante da política governamental, afetando, negativamente, a decisão de produção no campo (ALVES, 1991).

Já o segundo período de elevada variabilidade, iniciado em 2007, se relaciona com a última crise internacional, conhecida como a Grande Recessão. Tal fenômeno afetou negativamente a comovimentação das séries, como pode ser verificado na Figura 1, parte "d". Além disso, apesar da tendência geral de alta nos preços durante toda a amostra entre 2007 e 2012, há um movimento de correção, de meados de 2008 a início de 2010, gerado pela redução da demanda de exportações brasileiras (as exportações de carnes e vitelos para os Estados Unidos da América, por exemplo, caíram $30 \%$ neste período ${ }^{7}$ ).

Pode-se considerar, assim, que os preços bovinos passaram por duas quebras estruturais econômica e estatisticamente relevantes: a primeira após o Plano Real e a segunda após a crise internacional de 2007/2008. Nesse sentido, com intuito de manter os resultados do artigo solidamente fundamentados nos testes implementados até agora, seguem-se as datas descritas na Tabela 1 para a especificação com duas quebras, ou seja, 1995:07 e 2007:02.

São caracterizadas, nesse sentido, três conjunturas diferentes para o mercado de boi gordo no Brasil, que podem ser denominadas de: i) Conjuntura de instabilidade interna - variando de 1980 a 1995:06; ii) Conjuntura de estabilidade variando de 1995:07 a 2007:01; e iii) Conjuntura de instabilidade externa - variando de 2007:02 em diante. Na próxima seção, é avaliada a hipótese de integração dos preços do boi gordo, levando em conta esses diferentes contextos macroeconômicos.

7. Dados disponíveis em http://www.ers.usda.gov.

\subsection{Análise de estacionariedade, cointegração e assimetrias de ajustamento}

O primeiro passo para analisar a cointegração de mercados consiste em verificar se as séries de preços são estacionárias em nível. Para isso, aplicou-se o teste de Dickey-Fuller Aumentado (ADF) nas três conjunturas econômicas delineadas na subseção anterior, considerando drift e tendência determinística. O número de defasagens foi escolhido pelo Critério de Informação de Schwarz (BIC). Os resultados são reportados na Tabela 4.

No período de instabilidade interna, todos os estados analisados apresentaram séries estacionárias a 5\% de significância, com exceção de Mato Grosso. Descarta-se, portanto, a hipótese de integração entre Mato Grosso e os demais. Em relação às outras relações, Cati et al. (1999) mostram que, embora o período seja de persistência altista dos preços, as séries de preços do boi gordo apresentaram processo de reversão à média em razão dos chamados planos de estabilização "inliers".

Esses planos, que têm comportamento inverso aos preços hiperinflacionados, são choques aleatórios não estacionários proporcionais ao nível corrente das séries. Cati et al. (1999) reportam que os resultados do teste ADF são afetados pela presença ocasional de curtos, mas importantes planos de estabilização. Uma vez que os planos de estabilização deste período foram falhos, a inflação retornou à sua trajetória antiga.

O fato descrito é uma manifestação de um processo de "reversão forçada" à média, estatisticamente similar àquele que caracteriza as séries estacionárias. Logo, o teste ADF, neste contexto, tende a sugerir que o período de hiperinflação foi estacionário devido ao comportamento do governo de puxar para baixo os níveis de preços (CATI et al., 1999).

Em relação aos demais períodos, os resultados apontados na Tabela 4 indicam que as séries são não estacionárias, em nível, a 5\% de significância. Entretanto, todas as variáveis foram estacionárias em primeira diferença, indicando uma possível relação de cointegração entre as séries de preços do boi gordo. 
Tabela 4. Testes de raiz unitária (ADF) nas séries de preços do boi gordo

\begin{tabular}{|c|c|c|c|c|c|}
\hline \multicolumn{6}{|c|}{1980 a 1995:06 - Período de instabilidade interna } \\
\hline \multirow{2}{*}{$\begin{array}{l}\text { Variável } \\
\text { (em log) }\end{array}$} & \multirow{2}{*}{$\begin{array}{l}\text { Termos da } \\
\text { equação }\end{array}$} & \multirow{2}{*}{$\begin{array}{l}\text { Número de } \\
\text { defasagens }\end{array}$} & \multirow{2}{*}{$\begin{array}{l}\text { Estatística do teste } \\
\text { (ADF) }\end{array}$} & \multicolumn{2}{|c|}{ Valor Crítico } \\
\hline & & & & $5 \%$ & $1 \%$ \\
\hline $\mathrm{SP}^{* *}$ & CT & 0 & $-3,9366$ & $-3,4343$ & $-4,008$ \\
\hline $\mathrm{MG}^{* *}$ & СТ & 0 & $-3,8043$ & $-3,4343$ & $-4,008$ \\
\hline $\mathrm{RJ}^{* *}$ & СТ & 0 & $-3,9194$ & $-3,4342$ & $-4,008$ \\
\hline $\mathrm{ES}^{* *}$ & CT & 0 & $-3,7625$ & $-3,4342$ & $-4,008$ \\
\hline $\mathrm{MT}^{\mathrm{NS}}$ & CT & 0 & $-3,0844$ & $-3,4342$ & $-4,008$ \\
\hline $\mathrm{MS}^{* *}$ & CT & 0 & $-3,7323$ & $-3,4342$ & $-4,008$ \\
\hline $\mathrm{GO}^{* *}$ & CT & 1 & $-3,4877$ & $-3,4342$ & $-4,008$ \\
\hline \multicolumn{6}{|c|}{ 1995:07 a 2007:01 - Período de estabilidade } \\
\hline \multirow{2}{*}{$\begin{array}{l}\text { Variável } \\
\text { (em log) }\end{array}$} & \multirow{2}{*}{$\begin{array}{c}\text { Termos da } \\
\text { equação }\end{array}$} & \multirow{2}{*}{$\begin{array}{l}\text { Número de } \\
\text { defasagens }\end{array}$} & \multirow{2}{*}{$\begin{array}{l}\text { Estatística do teste } \\
\text { (ADF) }\end{array}$} & \multicolumn{2}{|c|}{ Valor Crítico } \\
\hline & & & & $5 \%$ & $1 \%$ \\
\hline $\mathrm{SP}^{\mathrm{NS}}$ & ST & 0 & $-0,7531$ & $-1,9431$ & $-2,5818$ \\
\hline $\mathrm{MG}^{\mathrm{NS}}$ & ST & 0 & $-0,9508$ & $-1,9431$ & $-2,5818$ \\
\hline $\mathrm{RJ}^{\mathrm{NS}}$ & ST & 1 & $-1,3873$ & $-1,9431$ & $-2,5818$ \\
\hline $\mathrm{ES}^{\mathrm{NS}}$ & ST & 0 & $-1,0395$ & $-1,9431$ & $-2,5818$ \\
\hline $\mathrm{MT}^{\mathrm{NS}}$ & ST & 1 & $-0,8183$ & $-1,9431$ & $-2,5818$ \\
\hline $\mathrm{MS}^{\mathrm{NS}}$ & ST & 0 & $-0,6897$ & $-1,9431$ & $-2,5818$ \\
\hline $\mathrm{GO}^{\mathrm{NS}}$ & ST & 0 & $-0,6537$ & $-1,9431$ & $-2,5818$ \\
\hline \multicolumn{6}{|c|}{ 2007:02 em diante - Período de instabilidade externa } \\
\hline \multirow{2}{*}{$\begin{array}{l}\text { Variável } \\
\text { (em log) }\end{array}$} & \multirow{2}{*}{$\begin{array}{l}\text { Termos da } \\
\text { equação }\end{array}$} & \multirow{2}{*}{$\begin{array}{l}\text { Número de } \\
\text { defasagens }\end{array}$} & \multirow{2}{*}{$\begin{array}{l}\text { Estatística do teste } \\
\text { (ADF) }\end{array}$} & \multicolumn{2}{|c|}{ Valor Crítico } \\
\hline & & & & $5 \%$ & $1 \%$ \\
\hline $\mathrm{SP}^{\mathrm{NS}}$ & CT & 0 & $-1,6941$ & $-3,4987$ & $-4,1446$ \\
\hline $\mathrm{MG}^{\mathrm{NS}}$ & C & 0 & $-2,5385$ & $-2,9069$ & $-3,5347$ \\
\hline $\mathrm{RJ}^{\mathrm{NS}}$ & C & 0 & $-1,6649$ & $-2,9069$ & $-3,5347$ \\
\hline $\mathrm{ES}^{\mathrm{NS}}$ & CT & 1 & $-2,6474$ & $-3,5107$ & $-4,1706$ \\
\hline $\mathrm{MT}^{\mathrm{NS}}$ & $\mathrm{C}$ & 0 & $-2,1762$ & $-2,9069$ & $-3,5349$ \\
\hline $\mathrm{MS}^{\mathrm{NS}}$ & C & 0 & $-2,3899$ & $-2,9069$ & $-3,5347$ \\
\hline $\mathrm{GO}^{\mathrm{NS}}$ & C & 1 & $-2,5282$ & $-2,9069$ & $-3,5349$ \\
\hline
\end{tabular}

Nota: $\mathrm{CT}=$ Constante e tendência determinística; $\mathrm{C}=$ Constante; $\mathrm{T}=$ Tendência determinística; $\mathrm{ST}=$ sem termos determinísticos. ${ }^{*}$ Significativo a $1 \%$; * Significativo a $5 \%$. SN = Não significativo.

Fonte: Resultados da pesquisa.

A fim de determinar as relações de longo prazo, especificou-se o estado de São Paulo como mercado central, pois, conforme apontam Cunha et al. (2010), este estado representa o maior mercado nacional de carne bovina, tem o maior número de frigoríficos e é o estado sede da Bolsa de Mercadorias \& Futuros (BM\&F), fatores que o colocam como a principal praça formadora de preços do boi gordo no Brasil.
A próxima etapa consiste em analisar os resíduos da regressão de longo prazo para determinar se as variações nos preços em São Paulo são repassadas às demais localidades. Utiliza-se, para isso, a abordagem de Enders e Siklos (2001), que considera a assimetria no ajustamento de preços e custos de transação. Emprega-se, neste estudo, o modelo M-TAR, conforme descrito na seção 3.1. Os resultados são mostrados na Tabela 5 . 
Tabela 5. Modelo M-TAR para cada subamostra

\begin{tabular}{|c|c|c|c|c|c|}
\hline \multicolumn{6}{|c|}{1980 a 1995:06 - Período de instabilidade interna } \\
\hline Mercado & $|\gamma|$ & $\rho_{1}$ & $\rho_{2}$ & $\rho_{1}=\rho_{2}=\mathbf{0}$ & $\rho_{1}=\rho_{2}$ \\
\hline SP-MG & 0,026 & $\begin{array}{c}-0,500^{*} \\
(0,098) \\
\end{array}$ & $\begin{array}{l}-0,650^{*} \\
(0,125) \\
\end{array}$ & $\begin{array}{c}22,377^{*} \\
{[8,237]} \\
\end{array}$ & $\begin{array}{l}1,088^{\mathrm{NS}} \\
{[8,129]}\end{array}$ \\
\hline SP-RJ & 0,015 & $\begin{array}{c}-0,392^{*} \\
(0,092) \\
\end{array}$ & $\begin{array}{l}-0,651^{*} \\
(0,112) \\
\end{array}$ & $\begin{array}{c}22,754^{*} \\
{[8,171]} \\
\end{array}$ & $\begin{array}{l}3,729^{\mathrm{NS}} \\
{[8,231]} \\
\end{array}$ \\
\hline SP-ES & 0,079 & $\begin{array}{l}-0,518^{*} \\
(0,087) \\
\end{array}$ & $\begin{array}{l}-0,725^{*} \\
(0,140) \\
\end{array}$ & $\begin{array}{c}26,547^{*} \\
{[8,189]}\end{array}$ & $\begin{array}{l}1,891^{\mathrm{NS}} \\
{[8,290]}\end{array}$ \\
\hline SP-MT & 0,052 & $\begin{array}{c}-0,469^{*} \\
(0,080)\end{array}$ & $\begin{array}{c}-0,902^{*} \\
(0,138) \\
\end{array}$ & $\begin{array}{c}33,283^{*} \\
{[8,156]}\end{array}$ & $\begin{array}{l}8,594^{*} \\
{[8,055]}\end{array}$ \\
\hline SP-MS & 0,056 & $\begin{array}{c}-0,492^{*} \\
(0,103) \\
\end{array}$ & $\begin{array}{l}-0,980^{*} \\
(0,119) \\
\end{array}$ & $\begin{array}{l}39,107^{*} \\
{[8,241]}\end{array}$ & $\begin{array}{l}11,984^{*} \\
{[8,127]}\end{array}$ \\
\hline SP-GO & 0,038 & $\begin{array}{l}-0,417^{*} \\
(0,094) \\
\end{array}$ & $\begin{array}{l}-0,848^{*} \\
(0,122) \\
\end{array}$ & $\begin{array}{c}29,641^{*} \\
{[8,092]}\end{array}$ & $\begin{array}{l}9,412 * \\
{[8,183]}\end{array}$ \\
\hline \multicolumn{6}{|c|}{ 1995:07 a 2007:01 - Período de estabilidade } \\
\hline Mercado & $|\gamma|$ & $\rho_{1}$ & $\rho_{2}$ & $\rho_{1}=\rho_{2}=\mathbf{0}$ & $\rho_{1}=\rho_{2}$ \\
\hline SP-MG & 0,029 & $\begin{array}{c}-0,335^{*} \\
(0,079) \\
\end{array}$ & $\begin{array}{l}-0,660^{*} \\
(0,158)\end{array}$ & $\begin{array}{c}16,650^{*} \\
{[8,115]}\end{array}$ & $\begin{array}{l}3,660^{\mathrm{NS}} \\
{[8,084]}\end{array}$ \\
\hline SP-RJ & 0,016 & $\begin{array}{c}-0,114^{\mathrm{NS}} \\
(0,103)\end{array}$ & $\begin{array}{l}-0,224^{*} \\
(0,056) \\
\end{array}$ & $\begin{array}{l}8,485^{*} \\
{[8,199]}\end{array}$ & $\begin{array}{l}0,918^{\mathrm{NS}} \\
{[8,211]}\end{array}$ \\
\hline SP-ES & 0,028 & $\begin{array}{c}-0,192^{*} \\
(0,055) \\
\end{array}$ & $\begin{array}{l}-0,518^{*} \\
(0,122) \\
\end{array}$ & $\begin{array}{l}14,346^{*} \\
{[8,073]}\end{array}$ & $\begin{array}{l}6,104^{\mathrm{NS}} \\
{[8,191]}\end{array}$ \\
\hline SP-MT & 0,023 & $\begin{array}{l}-0,236^{*} \\
(0,074) \\
\end{array}$ & $\begin{array}{l}-0,846^{*} \\
(0,158) \\
\end{array}$ & $\begin{array}{l}17,340^{*} \\
{[8,032]}\end{array}$ & $\begin{array}{l}13,543^{*} \\
{[8,110]}\end{array}$ \\
\hline SP-MS & 0,004 & $\begin{array}{c}-0,288^{*} \\
(0,091) \\
\end{array}$ & $\begin{array}{l}-0,457^{*} \\
(0,103) \\
\end{array}$ & $\begin{array}{l}13,504^{*} \\
{[8,242]}\end{array}$ & $\begin{array}{l}1,696^{\mathrm{NS}} \\
{[9,093]} \\
\end{array}$ \\
\hline SP-GO & 0,017 & $\begin{array}{c}-0,452^{*} \\
(0,113)\end{array}$ & $\begin{array}{l}-0,151^{*} \\
(0,064) \\
\end{array}$ & $\begin{array}{l}10,255^{*} \\
{[8,107]}\end{array}$ & $\begin{array}{l}5,700^{\mathrm{NS}} \\
{[8,095]}\end{array}$ \\
\hline \multicolumn{6}{|c|}{ 2007:02 em diante - Período de instabilidade externa } \\
\hline Mercado & $|\gamma|$ & $\rho_{1}$ & $\rho_{2}$ & $\rho_{1}=\rho_{2}=\mathbf{0}$ & $\rho_{1}=\rho_{2}$ \\
\hline SP-MG & 0,001 & $\begin{array}{l}0,002^{\mathrm{NS}} \\
(0,091)\end{array}$ & $\begin{array}{l}-0,253^{*} \\
(0,132) \\
\end{array}$ & $\begin{array}{l}1,917^{\mathrm{NS}} \\
{[8,244]}\end{array}$ & $\begin{array}{l}3,285^{\mathrm{NS}} \\
{[7,966]} \\
\end{array}$ \\
\hline SP-RJ & 0,014 & $\begin{array}{l}0,054^{\mathrm{NS}} \\
(0,039)\end{array}$ & $\begin{array}{l}-0,143^{*} \\
(0,067) \\
\end{array}$ & $\begin{array}{l}3,440^{\mathrm{NS}} \\
{[8,438]}\end{array}$ & $\begin{array}{l}6,844^{\mathrm{NS}} \\
{[7,957]} \\
\end{array}$ \\
\hline SP-ES & 0,026 & $\begin{array}{l}0,016^{\mathrm{NS}} \\
(0,046)\end{array}$ & $\begin{array}{c}-0,214^{\mathrm{NS}} \\
(0,144)\end{array}$ & $\begin{array}{l}1,205^{\mathrm{NS}} \\
{[8,421]}\end{array}$ & $\begin{array}{l}2,401^{\mathrm{NS}} \\
{[8,142]}\end{array}$ \\
\hline SP-MT & 0,023 & $\begin{array}{c}0,003^{\mathrm{NS}} \\
(0,045)\end{array}$ & $\begin{array}{c}0,1553^{\text {NS }} \\
(0,112) \\
\end{array}$ & $\begin{array}{l}0,967^{\mathrm{NS}} \\
{[8,316]} \\
\end{array}$ & $\begin{array}{l}1,652^{\mathrm{NS}} \\
{[8,057]}\end{array}$ \\
\hline SP-MS & 0,022 & $\begin{array}{c}0,054^{\mathrm{NS}} \\
(0,082)\end{array}$ & $\begin{array}{c}-0,392^{*} \\
(0,150) \\
\end{array}$ & $\begin{array}{l}3,825^{\mathrm{NS}} \\
{[8,529]}\end{array}$ & $\begin{array}{l}7,358^{\mathrm{NS}} \\
{[7,988]} \\
\end{array}$ \\
\hline SP-GO & 0,012 & $\begin{array}{c}0,095^{\mathrm{NS}} \\
(0,093)\end{array}$ & $\begin{array}{c}-0,018^{\mathrm{NS}} \\
(0,040) \\
\end{array}$ & $\begin{array}{l}0,638^{\mathrm{NS}} \\
{[8,370]}\end{array}$ & $\begin{array}{l}1,276^{\mathrm{NS}} \\
{[8,013]}\end{array}$ \\
\hline
\end{tabular}

Nota: * Significativo a, pelo menos, $5 \%$ de significância. NS = Não Significativo. Desvio padrão entre parênteses. Valor da estatística calculada entre colchetes.

Fonte: Resultados da pesquisa.

Percebe-se que, no período de instabilidade interna, pôde-se rejeitar a hipótese de que $\rho_{1}=\rho_{2}=$ 0 ; portanto, as séries são cointegradas. Este resultado era esperado, uma vez que todas as séries, com exceção do preço em Mato Grosso, foram estacionárias em nível, ou seja, I(0). Além disso, a visualização da Figura 2, parte $a$, fornece indicações nesse sentido. Afirma-se, portanto, que os mercados de boi gordo no Sudeste e Centro-Oeste, com exceção de Mato Grosso, foram integrados no período 1980-1995:06. Assim, a instabilidade interna que predominava nesses anos não foi suficiente para abalar a relação estável de longo prazo entre os preços nos diferentes estados. 
Ainda com respeito à primeira amostra, a hipótese de simetria dos choques, $\rho_{1}=\rho_{2}$, pôde ser rejeitada entre São Paulo e os estados do Centro-Oeste. Entretanto, não pôde ser rejeitada para os demais estados do Sudeste, pois $\rho_{1}=\rho_{2}$ foi não significativo. Percebe-se, então, que a distância geográfica entre os mercados determinou a significância da assimetria de ajustamento de preços. Naqueles mercados em que a hipótese de simetria foi rejeitada, percebe-se que choques menores que o threshold estimado tendem a desaparecer rapidamente, caso contrário, as perturbações exibiriam maior persistência (dado que $\left.\left|\hat{\rho}_{2}\right|>\left|\hat{\rho}_{1}\right|\right)$.

Ademais, a distância geográfica também pareceu influenciar o valor do threshold, estimado em, por exemplo, 5,6\% no mercado SP-MS e 3,8\% em SP-GO. Nestes mercados, foi confirmada a importância do modelo de Enders e Siklos (2001). Não obstante, mesmo choques abaixo desse threshold foram repassados, pois $\rho_{2}$ foi estatisticamente significativo em ambos os casos. No período hiperinflacionário, portanto, mesmo os choques de magnitude relativamente baixa foram suficientes para haver cointegração. Já nos demais mercados, pode-se optar pela análise de cointegração de Engle e Granger (1987), pois não houve assimetria no processo de ajustamento de preços.

No período de estabilidade, a hipótese $\rho_{1}=$ $\rho_{2}=0$ foi rejeitada em todas as relações, indicando cointegração no mercado de boi gordo. Não obstante, nota-se que o ajustamento de preços foi simétrico, pois a hipótese $\rho_{1}=\rho_{2}$ não foi rejeitada, com exceção de SP-MT (o threshold estimado foi de $2,3 \%$ ). Sendo assim, pode-se dizer que períodos de estabilidade econômica reduzem significativamente os custos de transação envolvendo o mercado de boi gordo brasileiro, pois se verifica um ajustamento simétrico na maioria dos mercados analisados.

Já com relação ao período de instabilidade externa, não se pode afirmar que os mercados de boi gordo foram sequer cointegrados, pois não se rejeitou a hipótese $\rho_{1}=\rho_{2}=0$. Em outras palavras, o mercado de boi gordo analisado neste estudo no período de instabilidade externa, caracterizado pela crise financeira de 2008, não apresentou equilíbrio de longo prazo.

Os resultados da Tabela 5, quando analisados de maneira dinâmica, mostram que houve queda significativa nos custos de transação após meados da década de 1990. Tal resultado corrobora o encontrado por Urso (2007), que explica que os frigoríficos têm se estabelecido próximo às regiões produtoras desde então, a fim de reduzir custos fiscais e de transporte do gado. Nesse sentido, a redução do valor do threshold verificado pelas estimações feitas está mais relacionada com o processo de mudança na estrutura produtiva do País (o que também explica a relação entre o valor do limiar e a distância geográfica).

Quanto à assimetria do ajustamento, os resultados indicam que ele foi mais visível na primeira amostra. Assim, a estrutura produtiva menos organizada e os pesados choques internos existentes nesse período contribuíram para um ajuste assimétrico de preços entre mercados espacialmente distantes. Perturbações relativamente pequenas tenderam a se dissipar com maior rapidez nesse contexto, enquanto choques exógenos de elevada magnitude geraram desvios persistentes dos preços de sua relação de equilíbrio de longo prazo.

A integração de preços, por outro lado, depende muito mais das condições do mercado externo, segundo os resultados encontrados. $\mathrm{Na}$ primeira amostra, por exemplo, as exportações conseguiram se contrapor à escassez de consumo interno (ver REZENDE, 1988). Adicionalmente, a partir de 1984, com o início de um longo período de estabilidade no mercado internacional, conhecido como a "Grande Moderação"8, a demanda externa tendeu a funcionar como âncora de segurança para os momentos de maior instabilidade interna. Tal processo de transmissão de preços continuou funcionando bem na segunda amostra, denominada "Conjuntura de estabilidade". Especificamente entre 2000 e 2007, as importa-

8. A Grande Moderação é o nome dado ao longo período de estabilidade da economia norte-americana iniciada em 1984. A esse respeito, recomenda-se a leitura de McConnell e Perez-Quiros (2000) e Stock e Watson (2002). 
ções, segundo dados da USDA, cresceram à taxa anual de $7 \%$, aproximadamente. Contudo, com o advento da última crise financeira que abalou fortemente as economias da Europa e dos Estados Unidos da América, percebe-se clara desordem nos preços do boi gordo nacional (veja Figura 2, parte $d$, a esse respeito).

\section{Considerações finais}

O presente artigo objetivou analisar a integração de preços do boi gordo nas regiões Sudeste e Centro-Oeste do País, no contexto de ajustes assimétricos e quebras estruturais. Para tanto, foram estimados modelos do tipo M-TAR (ENDERS e SIKLOS, 2001) em amostras previamente selecionadas com o método de quebras desconhecidas em sistemas de equações de Qu e Perron (2007). O período de análise envolveu os anos de 1980 a 2012, com dados mensais.

A principal constatação desta pesquisa é que o período de análise altera dramaticamente as conclusões a respeito da transmissão de choques, do valor do limiar (associado com os custos de transação) e da assimetria das respostas nos diversos mercados analisados. Percebeu-se, assim, que os custos de transação foram relevantes apenas na primeira amostra, que variou de 1980 a meados de 1995 (período hiperinflacionário). Esse resultado mostra que as políticas que visam a estabilidade do nível de preços são importantes para reduzir os custos de transação do mercado de boi gordo, aumentando, assim, sua eficiência.

De 1995 a 2007, o valor do threshold foi pequeno e não houve evidência de ajuste assimétrico de preços. Assim, os resultados contrastam com os previamente obtidos pela literatura, porém, desconsiderando a possibilidade de quebras estruturais, caso de Mattos et al. (2009), que encontraram efeito limiar significativo para todo o período de janeiro de 1972 a agosto de 2005 . Além disso, ao contrário do verificado por Cunha et al. (2010), não foram encontradas evidências de assimetrias no ajuste de preços para o mesmo período.
Quanto à integração dos preços, os resultados da presente pesquisa mostram que tal fenômeno foi observado nas duas primeiras amostras estimadas ou, em outras palavras, durante todo o período de janeiro de 1980 a janeiro de 2007 . Porém, na amostra de instabilidade interna, houve assimetria no ajuste entre São Paulo e os estados do Centro-Oeste. De 2007 em diante (na amostra que contém os anos de instabilidade gerada pela crise financeira de 2008), percebeu-se que a hipótese de integração de preços pôde ser rejeitada. Assim, a convergência de preços nos mercados de boi gordo no País parece ser extremamente dependente da conjuntura econômica externa. Nesse sentido, políticas públicas que visam aumentar a eficiência econômica nos mercados do boi gordo brasileiro deveriam tentar reduzir os efeitos das crises externas na produção interna, diminuindo as incertezas por meio de medidas anticíclicas de caráter fiscal ou monetário, por exemplo.

\section{Referências}

ABITANTE, K. G. Co-integração entre os mercados spot e futuro: evidências dos mercados de boi gordo e soja. RER, Rio de Janeiro, v. 46, n. 1, p. 75-96, 2008.

ALAM, M. J. et al. Measuring Market Integration in the Presence of Threshold Effect: The case of Bangladesh Rice Markets. AAEA Conference, Seattle, Washington, USA, 2012.

BAI, J. et al. Testing for and Dating Common Breaks in Multivariate Time Series. Review of Economic Studies, v. 65, p. 395-432, 1998.

BARRETT, C. B. Measuring Integration and Efficiency in International Agricultural Markets. Review of Agricultural Economics, v. 23, n. 1, p. 19-32, 2001.

BOX, G. E. P. e JENKINS, G. M. Time Series Analysis: Forecasting and Control. 4. ed. Wiley Publication, 1970.

BRESSAN, A. A. e LIMA, J. E. Modelos de previsão de preços aplicados aos contratos futuros de boi gordo na BM\&F. Nova Economia, v. 12, n. 1, p. 117-140, 2002.

BUENO, R. L. S. Econometria de séries temporais. São Paulo: Cengage Learning, 2008. 
CATI, et al. Unit Roots in the Presence of Abrupt Governmental Interventions with an Application to Brazilian Data. Journal of Applied Econometrics, v. 14, n. 1, p. 27-56, 1999.

CHAN, K. S. Consistency and limiting distribution of the least squares estimator of a threshold autoregressive model. The Annals of Statistics, v. 21, n. 1, p. 520-533, 1993.

CUNHA, D. A. et al. Integração Espacial do Mercado de Boi Gordo: uma Análise de Cointegração com Threshold. Análise Econômica, ano 28, n. 53, p. 251-267, 2010.

DICKEY, D. A. e FULLER, W. A. Distribution of the Estimators for Autoregressive Time Series With a Unit Root. Journal of the American Statistical Association, v. 74, n. 366, p. 427-431, 1979.

ENDERS, W. e SIKLOS, P. L. Cointegration and Threshold Adjustment. Journal of Business \& Economic Statistics, v. 19, n. 2, p. 166-176, 2001.

ENGLE, R. F. e GRANGER, C. W. J. Cointegration and error correction: representation, estimation and testing. Econometrica, v. 35, n. 1, p. 251-276, 1987.

FGV Dados, http://fgvdados.fgv.br/, Fundação Getúlio Vargas.

INSTITUTO BRASILEIRO DE GEOGRAFIA E ESTATÍSTICA, IBGE. ABATEBOVINOS, 2014. Disponível em: http://www.ibge.gov.br. [Acessado em: 10/05/2014].

JOHANSEN, S. Statistical analysis of cointegration vectors. Journal of Economics Dynamics and Control, v. 12, n. 2-3, p. 231-254, 1988.

MARGARIDO, M. A. et al. Análise dos impactos das cotações do dólar paralelo e do índice pluviométrico sobre os preços do boi gordo no estado de São Paulo. Revista Brasileira de Economia, v. 50, n. 2, p. 255-278, 1996.

MATTOS, L. B. et al. Integração espacial de mercados na presença de custos de transação: um estudo para o mercado de boi gordo em Minas Gerais e São Paulo. Revista de Economia e Sociologia Rural, v. 47, n. 1, p. 249274, 2009.
McCONNELL, M. e PEREZ-QUIROS, G. Output Fluctuations in the United States: What Has Changed Since the Early 1980's? American Economic Review, v. 90, n. 5, p. 1464-1476, 2000.

MEYER, J. Measuring market integration in the presence of transaction costs - a threshold vector error correction approach. Agricultural Economics, v. 31, n. 21, p. 327-334, 2004.

MEYER, J. e von CRAMON-TAUBADEL, S. Asymmetric Price Transmission: A Survey. Journal of Agricultural Economics, v. 55, n. 3, p. 581-661, nov. 2004.

MORAES, A. S. et al. Análise da eficiência do mercado futuro brasileiro de boi gordo usando co-integração. Revista de Economia e Sociologia Rural, v. 47, n. 3, p. 601614, 2009.

OBSTFELD, M. e TAYLOR, A. M. Nonlinear aspects of goods-market arbitrage and adjustment: Heckscher's commodity points revisited. Journal of the Japanese and International Economies, v. 11, n. 4, p. 441-479, 1997.

QU, Z. e PERRON, P. Estimating and testing structural changes in Multivariate regressions. Econometrica, v. 75, n. 2, p. 459-502, 2007.

REZENDE, G. C. Ajuste externo e agricultura no Brasil, 1981-86. Revista Brasileira de Economia, v. 42, n. 2, p. 101137, 1988.

. Do Cruzado ao Collor: Os planos de estabilização e a agricultura. Revista de Economia Política, v. 12, n. 2, p. 106-125, 1992.

STOCK, J. e WATSON, M. Has The Business Cycle Changed And Why? Cambridge: NBER Working Papers 9127, National Bureau of Economic Research, Inc., 2002.

URSO, F. S. P. A cadeia da carne bovina no Brasil: uma análise de poder de mercado e teoria da informação. 113p. 2007. Tese (Doutorado em Economia de Empresas) - Fundação Getúlio Vargas, 2007.

ZILLI, J. B. et al. Análise da cointegração e causalidade dos preços de boi gordo em diferentes praças nas regiões sudeste e centro-oeste do brasil. Revista de Economia Agrícola, v. 55, n. 2, p. 105-119, 2008. 
